\title{
Biocompatibility of a polymer based on Off-Stoichiometry Thiol-Enes + Epoxy (OSTE+) for neural implants
}

Fredrik Ejserholm ${ }^{1,2^{*}}$, John Stegmayr ${ }^{3,4}$, Patrik Bauer ${ }^{4}$, Fredrik Johansson ${ }^{2,4}$, Lars Wallman ${ }^{1,2}$, Martin Bengtsson ${ }^{1,2}$ and Stina Oredsson ${ }^{4}$

\begin{abstract}
Background: The flexibility of implantable neural probes has increased during the last 10 years, starting with stiff materials such as silicone to more flexible materials like polyimide. We have developed a novel polymer based on Off-Stoichiometry Thiol-Enes + Epoxy (OSTE+, consisting of a thiol, two allyls, an epoxy resin and two initiators), which is up to 100 times more flexible than polyimide. Since a flexible neural probe should be more biocompatible than a stiff probe, an OSTE+ probe should be more biocompatible than one composed of a more rigid material. We have investigated the toxicity of OSTE + as well as of OSTE + that had been incubated in water for a week $\left(\mathrm{OSTE}+\mathrm{H}_{2} \mathrm{O}\right)$ using MTT assays with mouse L929 fibroblasts. We found that OSTE+ showed cytotoxicity, but OSTE $+\mathrm{H}_{2} \mathrm{O}$ did not. Extracts were analyzed using LC-MS and GC-MS in order to identify leaked chemicals.

Results: Most constituents were found in extracts of OSTE + , whereas only initiators were found in OSTE $+\mathrm{H}_{2} \mathrm{O}$ extracts. The detected levels of each chemical found in the LC-MS and the GC-MS analysis were below the toxicity level when compared to MTT assays of all the individual chemicals, except for one of the initiators that had an $\mathrm{IC}_{50}$ value close to the detected levels.

Conclusion: Our notion is that the toxicity of OSTE+ was caused by one of the initiators, by impurities in the constituents or by synergistic effects of low doses of leaked chemicals. However, our conclusion is that if OSTE+ is incubated for one week in water, OSTE+ is not cytotoxic and suitable for further in vivo studies.
\end{abstract}

Keywords: Biocompatibility, In Vitro toxicity, LC-MS, Neural implant, Polymer, Off-Stoichiometry Thiol-Enes + EpoxyOSTE+

\section{Background}

The current research on neural probes for deep brain stimulation has created new possibilities to treat conditions such as chronic pain and motor symptoms associated with Parkinson's disease, in addition to enabling control of prosthetic limbs [1-4]. During the last couple of years, the development of implantable neural probes have been oriented towards flexible probes [5-14] made out of polymers, instead of the previously stiff probes made of silicon [15]. Since a more flexible probe will reduce the strain at the interface of the probe and the

\footnotetext{
* Correspondence: Fredrik.Ejserholm@bme.lth.se

'Department of Biomedical Engineering, Lund University, Box 118, Lund 221 00 , Sweden

${ }^{2}$ NeuroNano Research Centre, Lund University, Medicon VillageScheelevägen 8, Lund 223 81, Sweden

Full list of author information is available at the end of the article
}

tissue when compared to a more rigid probe, it should also reduce the tissue response to the probe, thus a more flexible neural probe should be more biocompatible then a more rigid probe $[13,16]$. Currently, the choice of material for both insulation as well as for the backbone of flexible intra-cortical neural probes has been Parylene $C$ or polyimide, and for flexible cortical neural probes: either Parylene $C$, polyimide or polydimethylsiloxane (PDMS). When comparing the flexibility according to Young's modulus, where a more rigid material has a higher Young's modulus value and a more flexible material has a lower value (Table 1), PDMS is more flexible than Parylene $\mathrm{C}$ and polyimide, even though all three materials have significant stiffness as compared to brain tissue. However, a technical drawback with PDMS is the difficulty in patterning it using UV-lithography, and 
Table 1 Young's modulus values of brain tissue, Parylene C, PDMS, polyimide and OSTE+ [12-15]

\begin{tabular}{ll}
\hline Material & Young's modulus \\
\hline Brain tissue & $0.5-1 \mathrm{kPa}$ \\
Parylene C & $4 \mathrm{GPa}$ \\
PDMS & $0.36-1.24 \mathrm{MPa}$ \\
Polyimide & $2.48 \mathrm{GPa}$ \\
OSTE+ @ $10^{\circ} \mathrm{C}$ & $1.9 \mathrm{GPa}$ \\
OSTE+ @ $37^{\circ} \mathrm{C}$ & $50 \mathrm{MPa}$ \\
\hline
\end{tabular}

thus it has to be molded, impairing the possibility of producing thin probes. In addition, a thin PDMS-based probe would be so fragile that it would likely probably not be possible to implant it into brain tissue.

Off-Stoichiometry Thiol-Enes + Epoxy (OSTE+) is a new polymer that was developed to be used in microfluidic devices [17] instead of PDMS, and we have then further developed it into a potential material for intra-cortical neural probes [18]. The Young's modulus of OSTE+ can be tuned by shifting the ratio between the constituents and it can easily be patterned using UV-lithography. We have developed a composition of OSTE+ that is as stiff as polyimide at $10{ }^{\circ} \mathrm{C}$, and roughly 100 times more flexible at a physiological temperature, $37{ }^{\circ} \mathrm{C}$ (Table 1) [18]. In UVlithography, OSTE+ is a negative photoresist and can be spin-coated into very thin layers where the thickness of the layer can be controlled by the spin speed. Another advantage OSTE+ affords is that the fabrication protocol is close to that of polyimide and it can therefore easily replace polyimide in current neural probes.

There are several studies showing the biocompatibility of Parylene C, PDMS and polyimide [19-23]. However, since OSTE+ is a new material, limited work has been done in this area [24].

In this study, our goals were to determine the biocompatibility of OSTE+ as well as investigate if there was leaching of constituents from the final polymer. The biocompatibility of various preparations of OSTE+ was tested using in vitro cytotoxicity assays (MTT assays) together with microscopy techniques and the analysis of possible constituents leaching from the materials was performed with liquid chromatography - mass spectroscopy (LC-MS) and gas chromatography - mass spectroscopy (GC-MS). This is an initial study of the cytotoxicity of OSTE+ and the results show that OSTE+, if handled correctly, renders low toxicity to cells, this warrants further studies in compliance with ISO 10993-1 in order to completely deduce the biocompatibility.

\section{Methods}

The manufacturing of the OSTE+ samples started with a molding step where the samples were cured in a PDMS mold using UV-light, followed by a post exposure bake at $65{ }^{\circ} \mathrm{C}$. Half of the OSTE+ samples were then incubated in MilliQ water (Millipore, Bedford, MA, USA) at room temperature for 7 days to allow non-bound constituents to leach out. These samples are called OSTE $+\mathrm{H}_{2} \mathrm{O}$ throughout this paper. All samples were then incubated in water at $37^{\circ} \mathrm{C}$ for $72 \mathrm{~h}$ (in compliance with ISO standard 10993-12) and the extractions were used in two different assay systems: chemical analysis and cytotoxicity analysis (in compliance with ISO standard 10993-5). The whole process is shown schematically in Fig. 1.

The cytotoxicity tests were performed using MTT assays in compliance with ISO standard 10993-5, and all samples were extracted using ISO standard 10993-12.

\section{Polymer fabrication \\ OSTE+}

OSTE+ is produced in a two-step polymerization reaction as previously described [18]. First, a fast UV-initiated radical polymerization step results in a cross-linked network of some of the thiol groups and of all the ene groups in the allyls. Then a thermal anionic polymerization step results in a fully polymerized network with the unreacted thiol groups and the epoxy resin.

In the first polymerization step, UV light was used o activate Lucirin ${ }^{\oplus}$ TPO-L (BASF, Germany) that initiated cross-linking between the thiol, tris[2-(3-mercap

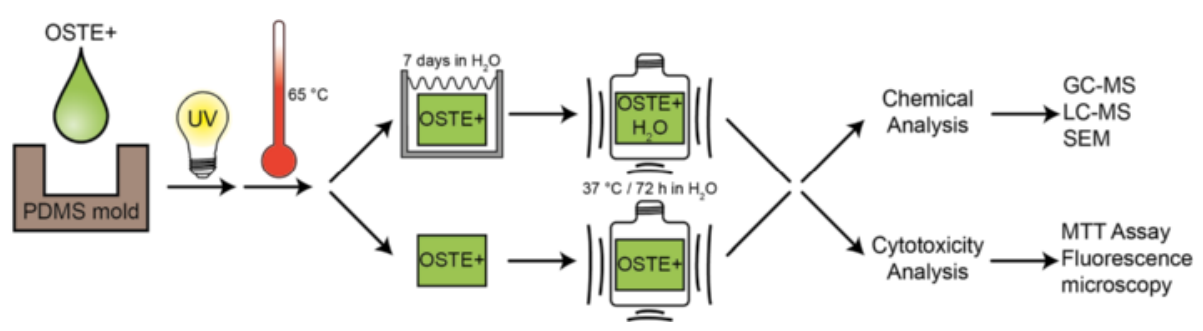

Fig. 1 A schematic representation of the procedure used in this study. A mixture of OSTE+ was shaped into blocks using a PDMS mold. The OSTE+ material was formed by a two-step polymerization process: first a UV-initiated step (exposure time of $40 \mathrm{~min}$ ) followed by a heat-initiated step in which the samples were placed in an oven at $65^{\circ} \mathrm{C}$ overnight. Half of the samples were placed in water for a week, allowing eventual unreacted constituents to leak out. Extractions were made by placing a sample of each material into a vial with water and the vial was then gently shaken at $37^{\circ} \mathrm{C}$ for $72 \mathrm{~h}$. The extractions were then used in chemical analysis and biological assays 
topropionyloxy)ethyl] isocyanurate (90\%, Sigma Aldrich, Germany), and the two allyls, trimethylolpropane diallyl ether (90\%, Sigma Aldrich) and 2,4,6-triallyloxy-1,3,5-triazine (97\%, Sigma Aldrich). In the second polymerization step, 1,5-diazabicyclo[4.3.0]non-5-ene (98\%, DBN, Sigma Aldrich) was used as the initiator for cross-linking between the thiol and the epoxy resin, D.E.N 341 Epoxy Novolac resin (Dow Chemicals, USA).

All ingredients were weighed according to a stoichiometric ratio of monomers of $1.5: 0.47: 0.53: 0.5$ for thiol, diallyl, triallyl and the epoxy resin, respectively. TPO-L and DBN were used at $0.2 \%$. Finally, $3 \%$ acetone (Sigma Aldrich) was added to the mixture. All ingredients were mixed and degassed under vacuum for $5 \mathrm{~min}$. The mixture was then poured into a pre-fabricated PDMS mold. The mold containing the mixture was then covered with a polycarbonate film and exposed to UV-light for 40 min using a Karl Suss MA4 mask aligner. The polycarbonate film was removed after the exposure and the OSTE+ pieces were hard-baked (to finalize the thiol-epoxy polymerization) in an oven at $65{ }^{\circ} \mathrm{C}$ overnight. The ratio of the different constituents results in an OSTE+ with a glass transition temperature of $39^{\circ} \mathrm{C}$ [18].

\section{Polyimide}

Polyimide was selected as a reference material since it is a material used in neural probes today $[8,9,11,13,20,22]$. Polyimide (Durimide 7505, FujiFilm, Belgium) was poured into a PDMS mold, followed by a $2 \mathrm{~h}$ soft-bake (to remove the solvents) at $85{ }^{\circ} \mathrm{C}$. The mold with polyimide was exposed to UV-light for 40 min using a Karl Suss MA4 mask aligner. The polyimide was then hard-baked (cured) in an oven at $200{ }^{\circ} \mathrm{C}$ for $4 \mathrm{~h}$. Finally, the polyimide pieces were rinsed in MilliQ water.

\section{HDPE}

A sheet of HDPE (Bay Plastics LTD, England) was cut into pieces using a milling machine. The pieces were cleaned with acetone (Sigma Aldrich) in an ultrasonic bath followed by a rinse in ethanol (Solveco, Sweden) and MilliQ water.

\section{Polymer extraction}

Extractions of polymer samples were obtained according to ISO standard 10993-12. The extraction was performed in cleaned borosilicate glass vials and water (LC-MS Ultra Chromasolv, Sigma Aldrich, for the chemical analysis and MilliQ water for the cytotoxicity analysis) was used as the extraction medium. The ratio of the surface area of the OSTE+, OSTE $+\mathrm{H}_{2} \mathrm{O}$, polyimide or HDPE samples and the water was $3 \mathrm{~cm}^{2} / \mathrm{ml}$. The samples were washed in MilliQ water before extraction. The vials were gently shaken at $37{ }^{\circ} \mathrm{C}$ for $72 \mathrm{~h}$. When the extraction solution was used in cytotoxicity tests, the polymer samples were first sterilized using an autoclave at $121{ }^{\circ} \mathrm{C}$ and the extractions were performed with sterile water.

\section{Chemical analysis \\ LC-MS analysis}

To obtain standards for the LC-MS analysis, an exact amount of each chemical used for the production of OSTE+ was dissolved in methanol (Sigma Aldrich) overnight (except acetone and D.E.N 431). The following day the solutions were diluted to a concentration of $500 \mu \mathrm{g} / \mathrm{ml}$ using $50 \%$ MilliQ water and $50 \%$ methanol. This was followed by a second dilution step to $50 \mu \mathrm{g} / \mathrm{ml}$ using MilliQ water. Acetone was not tested since it is not detectable in the LC-MS system used; D.E.N 431 was not tested since it is not water-soluble. To simulate the UV-lithography process of the fabrication of OSTE+, all standards were exposed to UV-light using a Karl Suss MA4 mask aligner for $40 \mathrm{~min}$. All standards, extractions (described above) of OSTE+, extractions of OSTE $+\mathrm{H}_{2} \mathrm{O}$ as well as blank samples, were analyzed using LC-MS.

A LC-MS system (QStar XL, Sciex, together with an Agilent 1100 LC system) was used with an Acquity CHS C18 $1.7 \mu \mathrm{m} 2.1 \times 50 \mathrm{~mm}$ column and a sample volume of $5 \mu \mathrm{l}$. The mass spectrometer was configured to scan 120-1000 Da at 2 scans/s. Acetonitrile (LC-MS, Chromasolv, Sigma Aldrich) and MilliQ water were used at a flow rate of $250 \mu \mathrm{l} / \mathrm{min}$. The concentration of acetonitrile in the mobile phase was: starting at $5 \%$ for $1 \mathrm{~min}$, ramp to $95 \%$ over $3 \mathrm{~min}$, hold for $2 \mathrm{~min}$, ramp down to $5 \%$ in $0.1 \mathrm{~min}$.

\section{GC-MS analysis}

To obtain standards for the GC-MS analysis, an exact amount of all constituents (except acetone) was dissolved in toluene (Sigma Aldrich and VWR). To simulate the UV-lithography process of the fabrication of OSTE+, all samples were exposed to UV-light for 40 min using a Karl Suss MA4 mask aligner. $400 \mu \mathrm{l}$ of the OSTE+ extractions or OSTE $+\mathrm{H}_{2} \mathrm{O}$ extractions (described above) was pipetted to a new vial containing $1 \mathrm{ml}$ of toluene. The toluene extraction samples were mixed using a vortex for $40 \mathrm{~h}$, followed by centrifugation for $1 \mathrm{~min}$. To ensure that all chemicals in the extracts were transferred into the organic phase, 2 samples of each extraction were made acidic by adding $50 \mu \mathrm{l}$ of $0.1 \mathrm{M} \mathrm{HCl}$ (VWR) and 2 samples of each extraction were made basic by adding $50 \mu \mathrm{l}$ of $0.1 \mathrm{M}$ $\mathrm{NaOH}$ (VWR) just before the addition of toluene to each extraction. The extracts spiked with $\mathrm{HCl}$ are referred to as $\mathrm{OSTE}+/ \mathrm{HCl}$ and $\mathrm{OSTE}+\mathrm{H}_{2} \mathrm{O} / \mathrm{HCl}$ throughout the paper and the extracts spiked with $\mathrm{NaOH}$ are referred to as OSTE $+/ \mathrm{NaOH}$ and OSTE $+\mathrm{H}_{2} \mathrm{O} / \mathrm{NaOH}$ throughout the paper. All samples and extracts together with a sample of pure toluene were analyzed using GC-MS. Acetone was 
not tested since it is used as a cleaning step in the GC-MS analysis.

All analyses were performed on a gas chromatograph (Agilent 6890) equipped with an injector in split mode at $250{ }^{\circ} \mathrm{C}$, equipped with an auto sampler (sample volume of $5 \mu \mathrm{l}$ ) and a mass spectrometry detector (Agilent 5973-N). The column used in the system was a HP- 5 ms fused silica capillary column (5\% phenyl-methylpolysiloxane) of $30 \mathrm{~m} \times 0.25 \mathrm{~mm}$ with a phase thickness of $0.25 \mu \mathrm{m}$. The temperature program of the column was: $50{ }^{\circ} \mathrm{C}$, hold for $1 \mathrm{~min}$, ramp to $300{ }^{\circ} \mathrm{C}$ over $10 \mathrm{~min}$, hold for $15 \mathrm{~min}$. The carrier gas used was helium at a flow rate of $1.2 \mathrm{ml} / \mathrm{min}$. The mass spectrometer was run in either scan mode (30-600 Da with $2.6 \mathrm{scan} / \mathrm{s}$ ) or in selected ion monitoring (SIM) mode, using mass to charge ratios $(\mathrm{m} / \mathrm{z})$ of $70,81,82,99,123,125,147,187,197,254,321$ together with a dwell time of $20 \mathrm{~ms}$.

\section{Scanning electron microscopy analysis of OSTE+}

Four OSTE+ pieces were cut into two halves. One half was put into MilliQ water for 7 days and then each pair was studied by scanning electron microscopy (SEM, SU 8010, Hitachi, Japan) to see if 7 days of incubation in water affected the surface of OSTE+.

\section{Cytotoxicity analysis}

Four different materials were tested in the MTT assay: OSTE + , OSTE $+\mathrm{H}_{2} \mathrm{O}$, polyimide and HDPE. Polyimide was selected since it is regarded as biocompatible and there are several studies that can be used for comparison. HDPE is a biocompatible material that sometimes is used as a negative control in different cell viability assays $[22,25,26]$.

\section{Cell culture}

The mouse fibroblast cell line L929 was purchased from American Type Culture Collection (ATCC, LGC standards $\mathrm{AB}$, Borås, Sweden) and was grown as a monolayer culture in complete cell culture medium, i.e. RPMI-1640 medium supplemented with $10 \%$ fetal bovine serum (FBS), $100 \mathrm{U} / \mathrm{ml}$ penicillin, $100 \mu \mathrm{g} / \mathrm{ml}$ streptomycin and $1 \mathrm{mmol} / \mathrm{l} \mathrm{L}$-glutamine, at $37{ }^{\circ} \mathrm{C}$ in $5 \% \mathrm{CO}_{2}$ in air. The cells were sub-cultured twice every week at a density of 12 500 cells $/ \mathrm{cm}^{2}$.

\section{Polymer extractions for cell culture}

The extracts were obtained as described above and kept at $4{ }^{\circ} \mathrm{C}$ for a maximum time of $24 \mathrm{~h}$ before use in the cytotoxicity assay with L929 cells. The extracts were diluted 1:2 in 2x concentrated RPMI-1640 medium supplemented with $20 \% \mathrm{FBS}, 200 \mathrm{U} / \mathrm{ml}$ penicillin, $200 \mu \mathrm{g} / \mathrm{ml}$ streptomycin and $2 \mathrm{mmol} / \mathrm{l} \mathrm{L}$-glutamine, i.e. a final extract concentration of $50 \%$ in $1 x$ concentrated RPMI-1640 containing $10 \%$ FBS, $100 \mathrm{U} / \mathrm{ml}$ penicillin, $100 \mu \mathrm{g} / \mathrm{ml}$ streptomycin and
$1 \mathrm{mmol} / \mathrm{l} \mathrm{L}$-glutamine, before addition to cell cultures Further dilutions of the $50 \%$ concentrated polymer extracts were done in $1 \mathrm{x}$ concentrated RPMI-1640 medium supplemented with $10 \% \mathrm{FBS}, 100 \mathrm{U} / \mathrm{ml}$ penicillin, $100 \mu \mathrm{g} / \mathrm{ml}$ streptomycin and $1 \mathrm{mmol} / \mathrm{l} \mathrm{L}$-glutamine.

\section{MTT assay - extract testing}

L929 cells were seeded in complete cell culture medium in 96-well plates (2000 cells/well in $180 \mu \mathrm{l}$ medium) and were then incubated at $37{ }^{\circ} \mathrm{C}$ in $5 \% \mathrm{CO}_{2}$ in humidified air for $24 \mathrm{~h}$. The medium was then removed and changed to medium containing the different extracts at concentrations ranging from 6.25-50 \% medium containing $2.5 \%$ dimethyl sulfoxide (DMSO: positive control) or control medium (complete cell culture medium with $0 \%$ extract). The cells were then kept at $37{ }^{\circ} \mathrm{C}$ in $5 \% \mathrm{CO}_{2}$ in humidified air for $72 \mathrm{~h}$ before addition of MTT to a final concentration of $0.5 \mathrm{mg} / \mathrm{ml}$. The 96 -well plates were incubated with MTT at $37{ }^{\circ} \mathrm{C}$ for $1 \mathrm{~h}$ before removal of the medium, and the cells with blue formazan crystals were then dissolved in DMSO. The following spectrometry reading at $540 \mathrm{~nm}$ was done using a SPECTRAmax M2 instrument (Molecular Devices, Sunnyvale, CA, USA) and analyzed using SoftMax ${ }^{\circ}$ Pro v. 4.6 (Molecular Devices). A number of 3-6 biological replicates (i.e. the testing of independent extracts of OSTE+, OSTE $+\mathrm{H}_{2} \mathrm{O}$, polyimide and HDPE) were used for all the treatments of the L929 cells and a number of 6 technical replicates (i.e. number of $\mathrm{n}$ ) from each extract were used for each biological replicate. After correcting all absorbance values for background, the percent of control was calculated as absorbance units in the presence of test compound as percentage of that in control. The results of the MTT assay are resumed to reflect the cell number, thus, $50 \%$ percent MTT reduction of control implies that there were $50 \%$ less cells at that treatment concentration [27].

\section{MTT assay - individual chemicals}

Each chemical used in the fabrication (except acetone), 1 or $0.1 \mathrm{mg}$, was added to a sterile flask and $1000 \mu \mathrm{l}$ sterile water was added. Further dilutions were made using sterile water. D.E.N 431 was not soluble in water and after shaking the sample and letting it stand for a while, only the water solution was used in the test. L929 cells were seeded in complete medium in 96-well plates (2000-3000 cells/well in $180 \mu \mathrm{l}$ medium) and the plates were incubated in a $\mathrm{CO}_{2}$ incubator for $24 \mathrm{~h}$ before addition of the chemicals. Indicated concentrations of the chemicals were added to the wells and the cells were incubated for $72 \mathrm{~h}$ at $37{ }^{\circ} \mathrm{C}$ in $5 \% \mathrm{CO}_{2}$ in humidified air. The dose response was evaluated using MTT as described above. 


\section{Phase contrast and fluorescence microscopy}

L929 cells were seeded in 12-well plates containing sterile glass coverslips, whereupon they were incubated at $37{ }^{\circ} \mathrm{C}$ in $5 \% \mathrm{CO}_{2}$ in humidified air for $24 \mathrm{~h}$. The growth medium was then removed and changed to growth medium without extract or containing the different polymer extracts (at a concentration of $50 \%$, obtained as described above). The cells were then incubated for $72 \mathrm{~h}$ before they were photographed with an Olympus CKX41 inverted phase contrast microscope (Olympus Corporation, Tokyo, Japan) equipped with an Olympus SC30 camera (Olympus Corporation) then analyzed using the software cellSense Standard version 1.4 (Olympus Corporation). The cells were then fixed in $3.7 \%$ paraformaldehyde for $15 \mathrm{~min}$ and washed with phosphate-buffered saline (PBS). The fixed cells were stained with Alexa Fluor 647-conjugated phalloidin in PBS containing $1 \%$ bovine serum albumin and $1 \%$ Tween-20 for $1 \mathrm{~h}$ and in PBS containing $1 \mu \mathrm{g} / \mathrm{ml}$ bisbenzimide for $1.5 \mathrm{~min}$ to visualize the cytoskeleton and nuclei, respectively. The glass coverslips were mounted on glass slides using Mowiol 4-88 and left in a refrigerator overnight. The samples were imaged with a LSM510 confocal laser scanning microscope (Carl Zeiss Microscopy GmbH, Oberkochen, Germany) equipped with a Hamamatsu R6357 photomultiplier (Hamamatsu Photonics K.K., Hamamatsu, Japan). A 405 nm diodepumped solid-state laser was used to excite the bisbenzimide and a band-pass filter of 420-480 nm was used for the emission. The Alexa Fluor 647-conjugated phalloidin was excited with a $633 \mathrm{~nm} \mathrm{HeNe}$ ion laser and a $650 \mathrm{~nm}$ long-pass filter was used for the emission. The cells were visualized by $\mathrm{z}$-stacks composed of single optical planes in high magnification and the images were analyzed with the software ZEN 2012 (black edition) version 8.0 (Carl Zeiss Microscopy GmbH).

\section{Results}

\section{Chemical analysis using LC-MS}

Standards of all constituents (except acetone and D.E.N 431), extracts of OSTE+, extracts of OSTE $+\mathrm{H}_{2} \mathrm{O}$ and blank samples were analyzed using LC-MS.
From the total ion current (TIC) chromatogram together with the molecular structure of each chemical and the mass to charge ratio the lower limit of detection (LOD) for each chemical could be calculated as well as the detection level for each chemical in the samples (Table 2). The LOD was calculated using a 3:1 ratio between signal/noise. Assuming that Beer Lambert's law was fulfilled, there should be a linear relationship between the recorded signal and the concentration. Then it was possible to calculate the detected concentration using a single-point calibration curve according to the following equation [28, 29]:

$$
\mathrm{C}=\frac{\mathrm{C}_{\mathrm{ref}}}{\mathrm{h}_{\mathrm{ref}}} \mathrm{h}
$$

where $\mathrm{C}$ is the detected concentration, $\mathrm{C}_{\mathrm{ref}}$ is the concentration of the standard, $\mathrm{h}_{\mathrm{ref}}$ is the peak height of the standard in the TIC and $h$ is the peak height detected in the sample for that specific mass to charge ratio that corresponds to the chemical in question.

TIC chromatograms from the LC-MS analysis of OSTE+ extracts, OSTE $+\mathrm{H}_{2} \mathrm{O}$ extracts and blank samples are shown in Fig. 2. Traces of all chemicals except trithiol were found in the OSTE+ extracts, while in the OSTE $+\mathrm{H}_{2} \mathrm{O}$ extracts only DBN and TPO-L were detected. It should be noted that each peak shown in Fig. 2 contains several different chemicals that contribute to the total height of the peak; hence the peak labeled "Diallyl" contains several different chemicals and diallyl is only a contributor in OSTE+, and is not found in OSTE $+\mathrm{H}_{2} \mathrm{O}$. Unidentified contributors to the peak heights imply that there were impurities in the chemicals or that they are derived from the chromatographic set up. When comparing the peak height of all the different chemicals in the OSTE+ and OSTE $+\mathrm{H}_{2} \mathrm{O}$ extractions, the detected levels of each chemical are either lower or below LOD for OSTE $+\mathrm{H}_{2} \mathrm{O}$. Acetone and D.E.N 431 were not analyzed since they are not water-soluble and standard curves could not be made.

\section{Chemical analysis using GC-MS}

Standards of all constituents, extracts of OSTE+, extracts of OSTE $+\mathrm{H}_{2} \mathrm{O}$ and blank samples were analyzed using

Table 2 Corresponding mass to charge ratio, LOD and detected level for each constituent found using LC-MS

\begin{tabular}{|c|c|c|c|c|}
\hline Constituent & $\mathrm{m} / \mathrm{z}$ & $\mathrm{LOD}(\mu \mathrm{g} / \mathrm{ml})$ & Detected level in OSTE+ extracts $(\mu \mathrm{g} / \mathrm{ml})$ & Detected level in OSTE $+\mathrm{H}_{2} \mathrm{O}$ extracts $(\mu \mathrm{g} / \mathrm{ml})$ \\
\hline DBN & 125 & 2.0 & 37.0 & 31.6 \\
\hline D.E.N 431 & $163,325-327,488-491$ & n,d. ${ }^{1}$ & $\mathrm{n}, \mathrm{d}$. & $\mathrm{n}, \mathrm{d}$. \\
\hline Diallyl & 215 & 2.0 & 2.4 & $b, d, l_{1}^{2}$ \\
\hline TPO-L & $121,147,317$ & 1.2 & 2.4 & 1.4 \\
\hline Triallyl & 250 & 1.7 & 2.4 & $b, d, l$. \\
\hline Trithiol & 524 & 0.7 & $b, d, l$. & $b, d, l$. \\
\hline
\end{tabular}

${ }^{1}$ n,d. not determined

${ }^{2} b, d, l$. below detection limit 


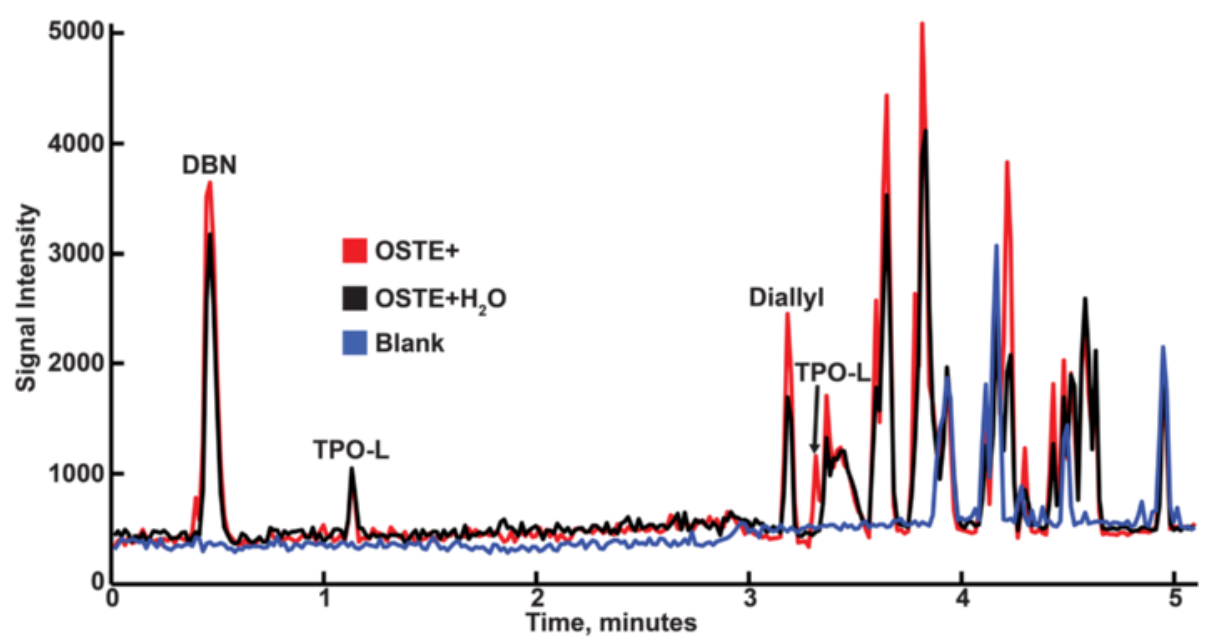

Fig. 2 Mean TIC chromatograms from LC-MS: red is OSTE+, black is OSTE $+\mathrm{H}_{2} \mathrm{O}$ and the blue is the blank sample, $n=2$. Analysis shows that one peak mainly contains DBN, two peaks that contain TPO-L and one peak contains some diallyl

GC-MS. The standards were analyzed using the GC-MS in scan mode. Peaks and different mass to charge ratios for all chemicals were obtained from this analysis. In order to increase the sensitivity of the GC-MS, all mass to charge ratios found when running the GC-MS in scan mode were used to run the GC-MS in SIM mode. Analysis of data from running the GC-MS in SIM mode allowed for the calculation of the lower limit of detection of all chemicals (see Table 3 ) in the same way as described for the LC-MS.

All extracts of OSTE + , OSTE $+\mathrm{H}_{2} \mathrm{O}, \mathrm{OSTE}+/ \mathrm{HCl}$, OSTE $+/ \mathrm{NaOH}, \quad$ OSTE $+\mathrm{H}_{2} \mathrm{O} / \mathrm{HCl}, \quad \mathrm{OSTE}+\mathrm{H}_{2} \mathrm{O} / \mathrm{NaOH}$ and all blank samples were run through the GC-MS both in SCAN mode and in SIM mode. No detectable traces of the constituents were found in any of the extracts.

\section{SEM analysis}

SEM images of OSTE + and $\mathrm{OSTE}+\mathrm{H}_{2} \mathrm{O}$ samples are shown in Fig. 3. Visible inspection revealed that the nanosized cracks are slightly bigger in the OSTE $+\mathrm{H}_{2} \mathrm{O}$ than in the OSTE+ sample.

\section{Cytotoxicity}

To evaluate the cytotoxicity of the OSTE+ and OSTE $+\mathrm{H}_{2} \mathrm{O}$ extracts in vitro, the mouse fibroblast cell line

Table 3 LOD of GC-MS (SIM mode)

\begin{tabular}{ll}
\hline Constituent & LOD of GC-MS \\
\hline DBN & $1.6 \mu \mathrm{g} / \mathrm{ml}$ \\
D.E.N 431 & $2.8 \mu \mathrm{g} / \mathrm{ml}$ \\
Diallyl & $4.1 \mu \mathrm{g} / \mathrm{ml}$ \\
TPO-L & $2.8 \mu \mathrm{g} / \mathrm{ml}$ \\
Triallyl & $2.4 \mu \mathrm{g} / \mathrm{ml}$ \\
Trithiol & $28.8 \mu \mathrm{g} / \mathrm{ml}$ \\
\hline
\end{tabular}

L929 was used in MTT assays. Extracts from HDPE and polyimide were used a negative controls and references samples, respectively, and 2.5\% DMSO was used as a positive control (Fig. 4a). The L929 cells were treated with concentrations ranging from 6.25-50\%, of the different polymer extracts for a total time of $72 \mathrm{~h}$. The data was analyzed using a 2-way ANOVA, comparing the data for each set $v s$. control and the results show a statistically significant and concentration-dependent decrease in MTT reduction in cells treated with OSTE+ extracts, compared to control cells (Fig. 4a). When diluted to $50 \%$, the OSTE+ extract lowered the MTT reduction about $40 \%$ compared to control implying that there were $40 \%$ fewer cells compared to control since MTT reduction is assumed to reflect the number of viable cells. At a $25 \%$ dilution, the MTT reduction was lowered about $15 \%$ compared to control. The same indications of toxicity seen after treatment with OSTE+ extracts were not found after treatment with OSTE $+\mathrm{H}_{2} \mathrm{O}$, polyimide or HDPE extracts (Fig. 4a). Additionally, to investigate effects on cell morphology, cells treated with the different polymer extracts (50\%) were studied using phase contrast and confocal microscopy. The cells photographed in the phase contrast microscope were non-stained and non-fixed (i.e. viable) whereas the cells photographed in the confocal microscope were fixed and stained with phalloidin and bisbenzimide to visualize the cytoskeleton (actin filaments) and the nuclei, respectively (Fig. 4c). No changes in morphology could be seen in cells treated with the polymer extracts for $72 \mathrm{~h}$, compared to control. Thus, the OSTE+ toxicity found in the MTT assay did not result in a morphological change.

To further study the toxicity of OSTE+ and to evaluate the difference in toxicity between OSTE + and $\mathrm{OSTE}+\mathrm{H}_{2} \mathrm{O}$, the individual chemicals used to produce OSTE+ were tested in MTT assays. As seen in Fig. 4b, DBN, diallyl, 

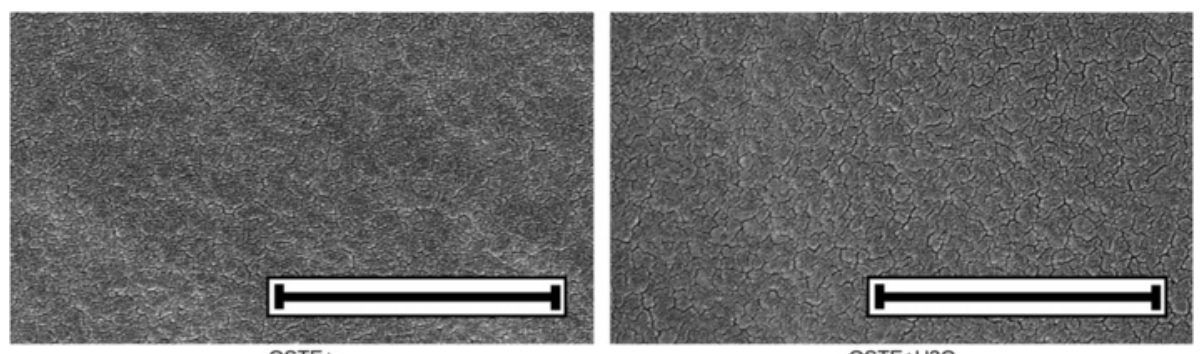

OSTE+

OSTE $+\mathrm{H} 2 \mathrm{O}$

Fig. 3 Scanning electron microscopy images of OSTE + and OSTE $+\mathrm{H}_{2} \mathrm{O}$. Scale bar $=1 \mu \mathrm{m}$
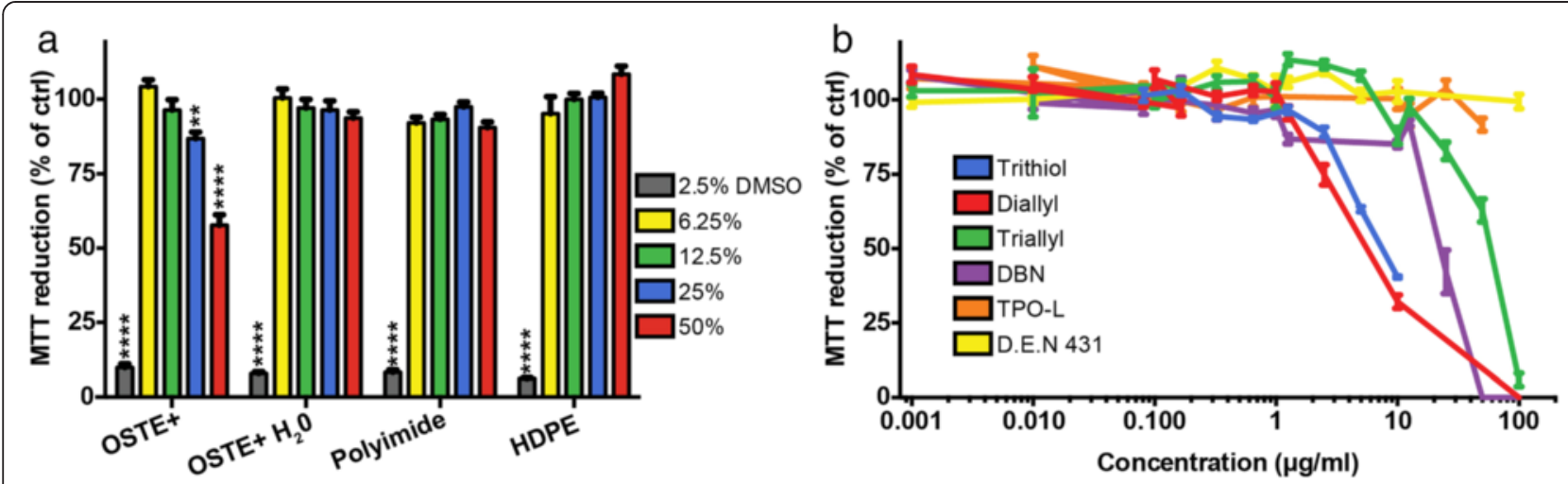

C
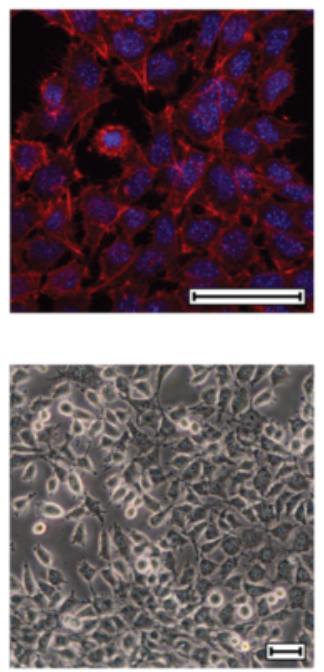

Control

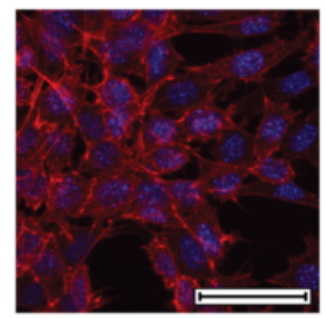

Confocal Microscopy
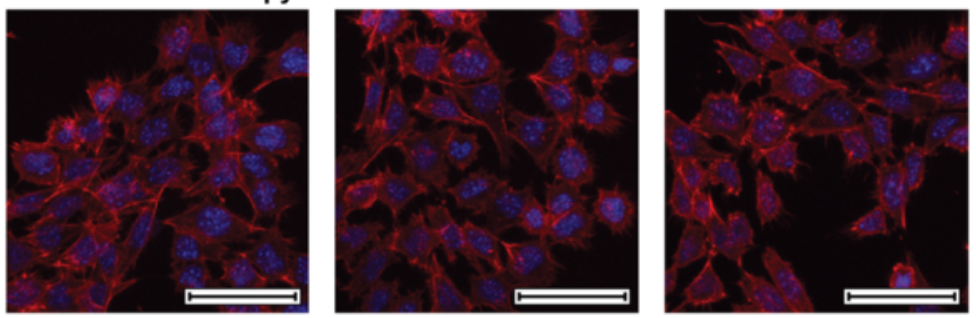

Phase Contrast Microscopy

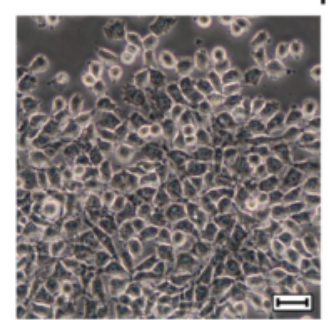

OSTE+

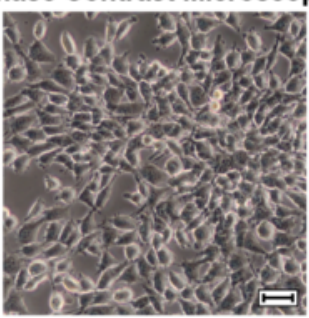

$\mathrm{OSTE}+\mathrm{H}_{2} \mathrm{O}$

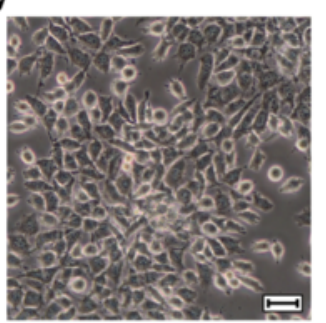

Polyimide

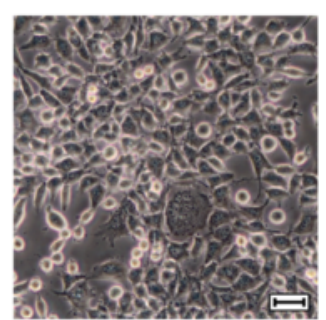

HDPE

Fig. 4 a Results from MTT assay tests using the L929 cell line. The L929 cells were seeded and allowed to attach in the wells of 96-well plates for $24 \mathrm{~h}$. The cells were then subjected to extraction solutions of OSTE,$+ \mathrm{OSTE}+\mathrm{H}_{2} \mathrm{O}$, polyimide and HDPE for $72 \mathrm{~h}$ at different concentrations $(6 \%$, $12.5 \%, 25 \%$ and $50 \%)$. DMSO at $2.5 \%$ was used as a positive control. The results are presented as mean values $(n=18-36)$ and the error bars represent \pm SEM. The data was analyzed using a 2-way ANOVA, comparing the data for each set vs. control where ${ }^{* *}$ represents a $P$-value $\leq 0.01$ and ${ }^{* * * *}$ represents a $P$-value $\leq 0.0001$. b The L929 cells were seeded and after $24 \mathrm{~h}$ treated for $72 \mathrm{~h}$ with the chemicals that were used in the production of OSTE+. Cell viability was assessed using the MTT assay. The results are presented as mean values $(n=6-18)$ and the bars represent \pm SEM. All chemicals, used as single agents, are non-toxic at concentrations below $1 \mu \mathrm{g} / \mathrm{ml}$. c Phase contrast (top row) and confocal microscopy (bottom row) images of mouse L929 cells exposed to extracts of OSTE+, OSTE $+\mathrm{H}_{2} \mathrm{O}$, polyimide and HDPE at a $50 \%$ concentration for $72 \mathrm{~h}$. The phase contrast images show viable and non-stained cells whereas the cells visualized with confocal microscopy were fixed and stained to show the actin cytoskeleton (red) and the nuclei (blue). The scale bars are equal to $50 \mu \mathrm{m}$. Images shown were taken in areas with similar cell densities 
trithiol and triallyl had effects on cell viability at concentrations above $1 \mu \mathrm{g} / \mathrm{ml}$. IC $\mathrm{IC}_{50}$ values for all constituents were obtained using linear regression in the area around the $50 \%$ MTT reduction (EXCEL, Table 4) and compared to the levels found when using LC-MS modified to represent extracts diluted to $50 \%$, i.e. the reported levels from Table 2 were divided by 2 . DBN was the only chemical were the detected level was close to the $\mathrm{IC}_{50}$ level.

\section{Discussion}

OSTE+ is a new polymer that is more flexible then other polymers used for neural probes. This should allow probes constructed in OSTE+ to follow the micro motions of the brain, hence increasing the biocompatibility of the neural probe [16]. Our group has previously shown that it is possible to make implantable neural probes in OSTE+ [18]. However there is one important question: is OSTE+ biocompatible? In our study we decided to give an answer to this question by using standardized biocompatibility toxicity tests used by the industry. Cytotoxicity was investigated using MTT assays with L929 cells in compliance with ISO standard 10993-5. The MTT assay was used to investigate the cytotoxicity of extracts of four different materials (OSTE + , OSTE $+\mathrm{H}_{2} \mathrm{O}$, polyimide and HDPE) and of the individual chemicals that were used in the OSTE+ fabrication process. The morphology of cells treated with extracts was investigated using phase contrast and confocal microscopy. GC-MC and LC-MS were used to analyze chemicals found in extracts of OSTE+ and extracts of OSTE $+\mathrm{H}_{2} \mathrm{O}$. SEM was used to investigate the surface structure of OSTE+ and OSTE $+\mathrm{H}_{2} \mathrm{O}$.

The results of the cytotoxicity test (Fig. 4a) imply that OSTE+ used directly after production may be toxic if not washed properly before implantation. The reduction of MTT is assumed to be proportional to cell number and thus at the highest concentration (extract diluted $50 \%)$, the OSTE+ extract significantly reduced the cell number thus implying an effect on cell proliferation. Using confocal microscopy and phase contrast microscopy we could not find any morphological changes imposed by any of the treatments (Fig. 4c). We cannot, however, exclude the possibility that higher magnification microscopy or the use of other cellular staining probes than phalloidin staining of actin may indicate morphological changes. To be able to draw conclusions about the exact mechanism of toxicity, more elaborate investigations have to be made. On the other hand, that may not be warranted since the toxicity disappeared when the OSTE+ samples were pre-incubated in water as an extra washing step.

The chemical analysis (LC-MS) showed that the watersoluble chemicals DBN, diallyl, triallyl and TPO-L were found in the extracts made from OSTE+. But only DBN and TPO-L were detected in the OSTE $+\mathrm{H}_{2} \mathrm{O}$ extracts, which is expected since they are only used as initiators in the process and are not immobilized in the final polymer network. Because the detected levels of most constituents were close to the respective LOD, some may still have leached out into the OSTE $+\mathrm{H}_{2} \mathrm{O}$ extracts. The $\mathrm{IC}_{50}$ value found for DBN (Table 4) is close to the detected levels of DBN in extracts of OSTE + and in extracts of OSTE $+\mathrm{H}_{2} \mathrm{O}$, and as seen in Fig. 4b the steep curve for DBN could explain the difference in toxicity between the extracts OSTE+ and the extracts of OSTE $+\mathrm{H}_{2} \mathrm{O}$. Comparing the $\mathrm{IC}_{50}$ values for diallyl and triallyl in the OSTE+ extracts with the detected levels (Table 4) the $\mathrm{IC}_{50}$ values are six times greater for diallyl and 60 times greater for triallyl. Hence, our conclusion is that neither diallyl nor triallyl are responsible for the toxicity found in the OSTE+ extracts. The lack of results from the extracts analyzed using the GC-MS is probably because most of the constituents are water soluble and thus were not extracted into the toluene phase from the water phase. Since acetone was used in the fabrication process, it is a possible candidate for toxicity. However, acetone was used as a $3 \%$ concentration in the fabrication mixture which was then degassed, exposed to UV-light and baked at $65{ }^{\circ} \mathrm{C}$ over night. Since acetone is a highly volatile substance, the concentration was likely lowered substantially. Remaining acetone may of course have leaked into the extract but a hypothetical calculation of concentration in the extract with no evaporation during the production process would give at hand a

Table $4 \mathrm{IC}_{50}$ values obtained from the dose response curves shown in Fig. $4 \mathrm{~b}$ and levels detected in the LC-MS analysis modified to represent extracts diluted to $50 \%$

\begin{tabular}{llll}
\hline Constituent & $\mathrm{IC}_{50}(\mu \mathrm{g} / \mathrm{ml})$ & $50 \%$ OSTE+ extracts $(\mu \mathrm{g} / \mathrm{ml})$ & $50 \%$ OSTE $+\mathrm{H}_{2} \mathrm{O}$ extracts $(\mu \mathrm{g} / \mathrm{ml})$ \\
\hline DBN & 23,1 & 18.5 & 15.8 \\
D.E.N 431 & $>100$ & $\mathrm{n}, \mathrm{d} .{ }^{1}$ & $\mathrm{n}, \mathrm{d}$. \\
Diallyl & 6.8 & 1.2 & $\mathrm{~b}, \mathrm{~d}, \mathrm{l}^{2}$ \\
TPO-L & $>100$ & 1.2 & 0.7 \\
Triallyl & 61.3 & 1.2 & $\mathrm{~b}, \mathrm{~d}, \mathrm{l}$. \\
Trithiol & 7.9 & $\mathrm{~b}, \mathrm{~d}, \mathrm{l}$. & $\mathrm{b}, \mathrm{d}, \mathrm{l}$. \\
\hline
\end{tabular}

${ }^{1} n$,d. not determined

${ }^{2} \mathrm{~b}, \mathrm{~d}, \mathrm{l}$. below detection limit 
maximum concentration in the medium of $0.2 \%$ which is below a concentration that has shown toxicity in cells $[30,31]$. Thus, we do not think acetone contributed to toxicity of OSTE+. The unidentified peaks in the LC-MS spectra (Fig. 2) support the existence of impurities, but since we were unable to identify the peaks their role in the toxicity cannot be determined. Neither have we tested possible synergistic effects of the low doses of the leaked compounds. Since we did not autoclave the samples used in the chemical testing, there could be a small variation between the extracts used in the MTT assays and in the chemical testing. However, the variation should be insignificant since the state of the material does not change when increasing the temperature above the temperature used in the hard-baking step.

Since oxygen will inhibit the UV-initiated polymerization step and PDMS has a high oxygen permeability [32, 33], the use of a spin-casting technique instead of PDMS molds should allow for a better polymerization of OSTE+ and decrease the amount of unreacted constituents in the final polymer. The surface analysis, using SEM (Fig. 3) shows that there was a small difference between OSTE+ and $\mathrm{OSTE}+\mathrm{H}_{2} \mathrm{O}$ samples. The nano-sized cracks were somewhat wider in the OSTE $+\mathrm{H}_{2} \mathrm{O}$ sample. In our previous work we did not use acetone in the mixture and we did not see any cracks when using that formula [18]. We therefore hypothesize that these cracks appeared during a fabrication step where acetone evaporated. Since acetone was added in order to make the mixture less viscous and easier to use in a mold, the use of spin casting should allow for a fabrication protocol without the use of acetone, which hopefully will prevent the formation of nano-sized cracks.

\section{Conclusion}

OSTE+ is a very promising material to use for neural probes because of its superior flexibility compared to other polymers used in neural probes today. The toxicity of OSTE+ extracts was presumably derived from DBN, unknown impurities in the constituents or from low dose synergetic effects of the constituents. However, by preincubating the final polymer in water for 7 days, OSTE+ was shown to be nontoxic to cells. The use of high-purity chemicals in the fabrication process, removal of acetone from the fabrication, the addition of a cleaning step in water during fabrication and the use of a silicon wafer as the substrate instead of PDMS should minimize the toxicity rendering implants made from OSTE+ nontoxic. In order to ensure the biocompatibility of OSTE+ for neural implants both short and long term in vivo tests have to be conducted.

\section{Competing interests}

We declare that we do not have any competing interests.

\section{Authors' contributions}

FE manufactured the samples, performed the LC-MS analysis, carried out the GC-MS experiments, did the SEM analysis and helped to draft and review the manuscript. JS carried out the MTT assays on the extracts together with PB. JS did the phase contrast and fluorescence microscopy. JS also contributed with text to the manuscript and revised the manuscript. FJ, LW and MB helped to draft as well as reviewed the manuscript. SO carried out the MTT assays of the individual chemicals, helped to draft and reviewed the manuscript. All authors read and approved the final manuscript.

\section{Acknowledgements}

This project was sponsored by two grants from the Swedish Research Council (project number 80337401 and project number 60012701; 60012701 is a Linnaeus grant) and one grant from The Knut and Alice Wallenberg Foundation (project number: KAW 2004.0119). We would also like to thank Professor emeritus Jan Åke Jönsson and Margareta Sandahl at the Centre for Analysis and Synthesis, Department of Chemistry at Lund University, for all the help with the GC-MS analysis.

\section{Author details}

${ }^{1}$ Department of Biomedical Engineering, Lund University, Box 118, Lund 221 00 , Sweden. ${ }^{2}$ NeuroNano Research Centre, Lund University, Medicon VillageScheelevägen 8, Lund 223 81, Sweden. ${ }^{3}$ Department of Laboratory Medicine, Lund University, Box 118, Lund 221 00, Sweden. ${ }^{4}$ Department of Biology, Lund University, Box 118, Lund 221 00, Sweden.

Received: 27 March 2015 Accepted: 4 September 2015 Published online: 21 September 2015

\section{References}

1. Rodriguez-Oroz MC, Obeso JA, Lang AE, Houeto JL, Pollak P, Rehncrona S, et al. Bilateral deep brain stimulation in Parkinson's disease: a multicentre study with 4 years follow-up. Brain. 2005;128:2240-9.

2. Vlamings $R$, Visser-Vandewalle $V$, Koopmans $G$, Joosten EAJ, Kozan R, Kaplan $S$, et al. High frequency stimulation of the subthalamic nucleus improves speed of locomotion but impairs forelimb movement in Parkinsonian rats. Neuroscience. 2007;148:815-23.

3. Schwartz AB. Cortical neural prosthetics. Annu Rev Neurosci. 2004;27:487-507.

4. Nandi D, Liu X, Joint C, Stein J, Aziz T. Thalamic field potentials during deep brain stimulation of periventricular gray in chronic pain. Pain. 2002;97:47-51.

5. Blau A, Murr A, Wolff S, Sernagor E, Medini P, lurilli G, et al. Flexible, allpolymer microelectrode arrays for the capture of cardiac and neuronal signals. Biomaterials. 2011;32:1778-86.

6. Ochoa M, Wei P, Wolley AJ, Otto KJ, Ziaie B. A hybrid PDMS-Parylene subdural multi-electrode array. Biomed Microdevices. 2013;15:437-43.

7. Ejserholm F, Köhler P, Bengtsson M, Jörntell H, Schouenborg J, Wallman L. A polymer based electrode array for recordings in the cerebellum. 2011 5th Int IEEE/EMBS Conf Neural Eng 2011:376-9.

8. Rousche PJ, Pellinen DS, Pivin DP, Williams JC, Vetter RJ, Kipke DR. Flexible polyimide-based intracortical electrode arrays with bioactive capability. IEEE Trans Biomed Eng. 2001;48:361-71.

9. Lee K-K, He J, Singh A, Massia S, Ehteshami G, Kim B, et al. Polyimide-based intracortical neural implant with improved structural stiffness. J Micromech Microeng. 2004;14:32-7.

10. Stieglitz T, Rubehn B, Henle C, Kisban S, Herwik S, Ruther P, et al. Brain-computer interfaces: an overview of the hardware to record neural signals from the cortex. Elsevier. 2009;175:249-66.

11. Mercanzini A, Cheung K, Buhl DL, Boers M, Maillard A, Colin P, et al. Demonstration of cortical recording using novel flexible polymer neural probes. Sensors Actuators A Phys. 2008;143:90-6.

12. Seymour JP, Langhals NB, Anderson DJ, Kipke DR. Novel multi-sided, microelectrode arrays for implantable neural applications. Biomed Microdevices. 2011;13:441-51.

13. Wester BA, Lee RH, LaPlaca MC. Development and characterization of in vivo flexible electrodes compatible with large tissue displacements. J Neural Eng. 2009:6:024002.

14. Ejserholm F, Köhler PER, Granmo M, Schouenborg J, Bengtsson M, Wallman L. $\mu$-Foil Polymer Electrode Array for Intracortical Neural Recordings. IEEE J Transl Eng Heal Med 2014;2.

15. Wise KD, Najafi K. Microfabrication Techniques for Integrated Microsystems Sensors. Science (80-). 1991;254:1335-42. 
16. Subbaroyan J, Martin DC, Kipke DR. A finite-element model of the mechanical effects of implantable microelectrodes in the cerebral cortex. J Neural Eng. 2005;2:103-13.

17. Carlborg CF, Haraldsson T, Öberg K, Malkoch M, van der Wijngaart W. Beyond PDMS: off-stoichiometry thiol-ene (OSTE) based soft lithography for rapid prototyping of microfluidic devices. Lab Chip. 2011;11:3136-47.

18. Ejserholm F, Vastesson a., Haraldsson T, van der Wijngaart W, Schouenborg J, Wallman L, et al. A polymer neural probe with tunable flexibility. 2013 6th Int IEEE/EMBS Conf Neural Eng 2013:691-4.

19. Thangawng AL, Ruoff RS, Swartz MA, Glucksberg MR. An ultra-thin PDMS membrane as a bio/micro-nano interface: fabrication and characterization. Biomed Microdevices. 2007;9:587-95.

20. Jiang X, Sui X, Lu Y, Yan Y, Zhou C, Li L, et al. In vitro and in vivo evaluation of a photosensitive polyimide thin-film microelectrode array suitable for epiretinal stimulation. J Neuroeng Rehabil. 2013;10:48.

21. Rubehn B, Stieglitz T. In vitro evaluation of the long-term stability of polyimide as a material for neural implants. Biomaterials. 2010;31:3449-58.

22. Bae SH, Che J-H, Seo J-M, Jeong J, Kim ET, Lee SW, et al. In vitro biocompatibility of various polymer-based microelectrode arrays for retinal prosthesis. Invest Ophthalmol Vis Sci. 2012;53:2653-7.

23. Chang TYC, Yadav VG, De Leo S, Mohedas A, Rajalingam B, Chen C-L, et al. Cell and protein compatibility of parylene-C surfaces. Langmuir. 2007;23:11718-25.

24. Errando-Herranz C, Vastesso A, Zelenina M, Pardon G, Bergström G, van der Wijngaart W, et al. Biocompatibility of OSTE polymers studied by cell growth experiments. 17th Int Conf Miniaturized Syst Chem Life Sci 2013:143-5

25. Prasitsilp M, Siriwittayakorn T, Molloy R, Suebsanit N, Siriwittayakorn P, Veeranondha S. Cytotoxicity study of homopolymers and copolymers of 2-hydroxyethyl methacrylate and some alkyl acrylates for potential use as temporary skin substitutes. J Mater Sci Mater Med. 2003;14:595-600.

26. Briganti E, Losi P, Raffi A, Scoccianti M, Munaò A, Soldani G. Silicone based polyurethane materials: a promising biocompatible elastomeric formulation for cardiovascular applications. J Mater Sci Mater Med. 2006;17:259-66.

27. Mosmann T. Rapid colorimetric assay for cellular growth and survival: application to proliferation and cytotoxicity assays. J Immunol Methods. 1983;65:55-63

28. Kimura M, Rodriguez-Amaya DB. A scheme for obtaining standards and HPLC quantification of leafy vegetable carotenoids. Food Chem. 2002;78:389-98.

29. Poole CF. The Essence of Chromatography. Amsterdam: Elsevier Science B.V; 2003.

30. Maes J, Verlooy L, Buenafe OE, de Witte PA, Esquerra CV, Crawford AD. Evaluation of 14 organic solvents and carriers for screening applications in zebrafish embryos and larvae. PLoS One. 2012;7:e43850.

31. Huberman E, Aspiras L, Heidelberger C, Grover PL, Sims P. Mutagenicity to Mammalian Cells of Epoxides and Other Derivatives of Polycyclic Hydrocarbons. Proc Natl Acad Sci. 1971:68:3195-9.

32. Dendukuri D, Panda P, Haghgooie R, Kim JM, Hatton TA, Doyle PS. Modeling of oxygen-inhibited free radical photopolymerization in a PDMS microfluidic device. Macromolecules. 2008:41:8547-56.

33. Castro D, Ingram P, Kodzius R, Conchouso D, Yoon E, Foulds IG. Characterization of solid UV cross-linked PEGDA for biological applications. 2013 IEEE 26th Int Conf Micro Electro Mech Syst 2013:457-60.

\section{Submit your next manuscript to BioMed Central and take full advantage of:}

- Convenient online submission

- Thorough peer review

- No space constraints or color figure charges

- Immediate publication on acceptance

- Inclusion in PubMed, CAS, Scopus and Google Scholar

- Research which is freely available for redistribution

Submit your manuscript at www.biomedcentral.com/submit 